\title{
Motivational factors underlying aversive Pavlovian-instrumental transfer
}

\author{
Vinn D. Campese, ${ }^{1}$ Ian T. Kim, ${ }^{2,3}$ Botagoz Kurpas, ${ }^{4}$ Lauren Branigan, ${ }^{5}$ Cassandra Draus, ${ }^{5}$ \\ and Joseph E. LeDoux ${ }^{5,6}$ \\ ${ }^{1}$ Department of Psychology, University of Evansville, Evansville, Indiana 47722, USA; ${ }^{2}$ Behavioral and Neural Sciences Graduate \\ Program, Rutgers University-Newark, Newark, New Jersey 07102, USA; ${ }^{3}$ Center for Molecular and Behavioral Neuroscience, Rutgers \\ University-Newark, Newark, New Jersey 07102, USA; ${ }^{4}$ Department of Psychology, Kingsborough College, Brooklyn, New York 11235 , \\ USA; ${ }^{5}$ Center for Neural Science, New York University, New York, New York 10010, USA; ${ }^{6}$ Emotional Brain Institute, Nathan Kline \\ Institute for Psychiatric Research, Orangeburg, New York 10962, USA
}

\begin{abstract}
While interest in active avoidance has recently been resurgent, many concerns relating to the nature of this form of learning remain unresolved. By separating stimulus and response acquisition, aversive Pavlovian-instrumental transfer can be used to measure the effect of avoidance learning on threat processing with more control than typical avoidance procedures. However, the motivational substrates that contribute to the aversive transfer effect have not been thoroughly examined. In three studies using rodents, the impact of a variety of aversive signals on shock-avoidance responding (i.e., two-way shuttling) was evaluated. Fox urine, as well as a tone paired with the delivery of the predator odor were insufficient modulatory stimuli for the avoidance response. Similarly, a signal for the absence of food did not generate appropriate aversive motivation to enhance shuttling. Only conditioned Pavlovian stimuli that had been paired with unconditioned threats were capable of augmenting shock-avoidance responding. This was true whether the signaled outcome was the same (e.g., shock) or different (e.g., klaxon) from the avoidance outcome (i.e., shock). These findings help to characterize the aversive transfer effect and provide a more thorough analysis of its generalization to warning signals for different kinds of threats. This feature of aversive motivation has not been demonstrated using conventional avoidance procedures and could be potentially useful for applying avoidance in treatment settings.
\end{abstract}

Aversive Pavlovian conditioning, also commonly called defensive (or fear) conditioning has been utilized as a model of human emotional dysregulation for decades. By repeatedly pairing a neutral stimulus (e.g., tone) with an aversive outcome (e.g., shock), the tone eventually produces anticipation of shock and elicits conditioned responding (e.g., freezing, changes in heart rate, endogenous analgesia). Many studies using this behavioral procedure across a variety of species have allowed for the identification of important structures and pathways in the central nervous system crucial for the acquisition and expression of this form of learning (Maren and Fanselow 1996; Herry and Johansen 2014; Krabbe et al. 2018). As this understanding grew, identifying ways to reduce conditioned responses using stimulus exposure became a focus of the field because of its high clinical relevance to treating humans suffering from disorders of fear and anxiety (Bouton 2004; Rauch et al. 2006; Milad and Quirk 2012; Kim and Jung 2018; Meulders 2020). While this approach does reduce defensive behaviors over the course of treatment, recovery effects based on context, time, and internal state make extinction less appealing as a long-term treatment option for humans (Bouton et al. 2006; Delgado et al. 2006; Hofmann 2007; Beckers et al. 2013; Markowitz and Fanselow 2020). In response, interest in active avoidance and aversive instrumental motivation began to reemerge as an alternative approach to reducing defensive responding (Bravo-Rivera et al. 2014; Gillan et al. 2014; Krypotos et al. 2015; LeDoux et al. 2016).

In contrast to Pavlovian conditioning, where the subject passively experiences tone-shock pairings, active avoidance uses a response (e.g., lever press or shuttling) that can terminate trials

\section{Corresponding author: vc44@evansville.edu}

Article is online at http://www.learnmem.org/cgi/doi/10.1101//m.052316.120. and prevent harm. As the subject transitions from passive to active response modes, defensive behaviors (i.e., freezing) are gradually reduced. While this may seem an encouraging analog to extinction for understanding how defensive reactivity can be attenuated over time, active avoidance studies are often difficult to interpret and have a number of conceptual and control problems that can complicate the issue further (Sidman 1953; Rescorla and Solomon 1967; Bolles 1972; Fanselow and Lester 1988; Fanselow 1997; Kim et al. 2006; LeDoux et al. 2016; Cain 2019). Use of an aversive Pavlovian-instrumental transfer procedure offers analysis of aversive motivation without many of the problems normally associated with active avoidance studies (Campese et al. 2013, 2014). However, while a handful of studies have shown the capacity for an aversive conditioned stimulus to modulate avoidance behavior, a systematic analysis of this phenomenon is, as of yet, lacking in the literature. The purpose of the studies below is to provide a better understanding of the motivational factors that contribute to the ability of an aversive conditioned cue to control active avoidance responses. This was done by examining whether motivational control of avoidance extends to (1) nonspecific aversive conditioned stimuli, (2) predator odor, (3) cues for predator odor, and (4) associatively and motivationally opposite, yet functionally equivalent cues (i.e., an appetitive inhibitor). The studies reported below suggest that aversive motivational control over avoidance is

(C) 2020 Campese et al. This article is distributed exclusively by Cold Spring Harbor Laboratory Press for the first 12 months after the full-issue publication date (see http://learnmem.cshlp.org/site/misc/terms.xhtml). After 12 months, it is available under a Creative Commons License (Attribution-NonCommercial 4.0 International), as described at http://creativecommons.org/licenses/by-nc/ $4.0 \%$. 
limited to previously neutral cues that have acquired aversive properties via pairings with an aversive outcome.

\section{Results}

\section{Shock-avoidance motivation generalizes to signals for other threats}

Studies of Pavlovian-instrumental transfer (PIT) have predominantly been done using appetitive motivation (Estes 1943, 1948; Rescorla 1994; Holland 2004; Corbit et al. 2007; Corbit and Balleine 2016). The findings from these studies have contributed to an immensely rich understanding of the psychological and neural structures underlying various forms of appetitive or rewardbased motivation. These studies benefit from the wide variety of appetitive reinforcers available and the readiness with which many distinct behaviors can be shaped when rewarded with different kinds of foods (Kruse et al. 1983; Dickinson et al. 1996; Ranaldi et al. 2009). Using these response-outcome options, appetitive PIT studies have demonstrated that different forms of motivation (i.e., sensory specific as opposed to general motivation) depend on different pathways in the brain (Hall et al. 2001; Holland and Gallagher 2003; Corbit et al. 2007; Shiflett and Balleine 2010). These findings have provided valuable insight toward our understanding of appetitive motivation and instances of its dysregulation (Dickinson et al. 2000; Wyvell and Berridge 2001; Holland 2004; Wise and Koob 2014).

On the other hand, aversive motivation has not been approached from this perspective. Because it is more limited in the range of response options, and fewer perceptually distinct outcomes are studied, it can be difficult to isolate sensory specific encoding. However, some studies have shown that other kinds of aversive outcomes can potentially be used in a similar manner to more thoroughly probe the underlying psychology of aversive motivation (Rescorla 1974; Diaz-Mataix et al. 2011; Campese et al. 2019). For example, loud klaxon horns have been used as an unconditioned stimulus in previous studies of aversive PIT (Campese et al. 2017a). These studies analyzed the effects of Pavlovian extinction on transfer using a within-subjects design where a second Pavlovian cue was paired with shock. Thus, the possibility remains that the capacity of the cue associatively linked to the klaxon to motivate avoidance can be attributed to generalization from the shock cue.

To address this, we trained two separate groups of rats to associate tone with shock, or tone with klaxon. In one subset of these animals, Pavlovian freezing tests were conducted the following day, whereas the remainder underwent Sidman avoidance for shock and were subsequently tested for transfer (see Fig. 1). This study found that freezing to the tone in both the klaxon and shock groups was statistically equal $\left(t_{(14)}=0.06, P=0.95\right)$ (see Fig. $1 \mathrm{~B}$ ). Both groups also showed (see Fig. 1C) increased avoidance responding over training blocks $\left(F_{\text {Block }(4,56)}=12.79, P<0.001\right)$, the rates of which were comparable $\left(F_{\operatorname{Group}(1,14)}=0.89, P=0.36\right.$, $\left.F_{\text {Block }{ }^{*} \operatorname{Group}(4,56)}=2.21, P=0.09\right)$. Finally, transfer testing revealed more responding during the stimulus compared with the baseline period to a similar degree for both groups $\left(F_{\text {Interval }(1,14)}=5.45, P=\right.$ $\left.0.04, F_{\text {Group }(1,14)}=1.97, P=0.18, F_{\text {Interval }}^{*} \operatorname{Group}(1,14)=1.30, P=0.27\right)$ (see Fig. 1D).

\section{Fox urine does not influence rates of two-way shuttle box} shock-avoidance

In order to determine whether the ability of conditioned threat signals to augment active shock-avoidance extends to unlearned threat signals, a group of subjects were exposed to fox urine in the avoidance apparatus after successful shock avoidance training
A

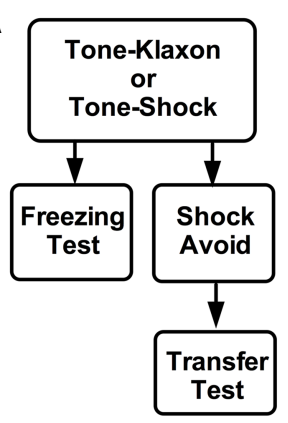

B Freezing

C
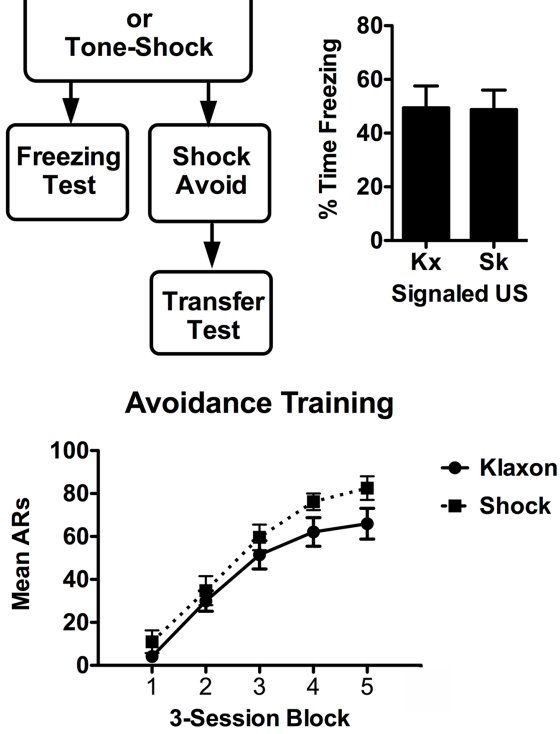

D

Transfer Testing

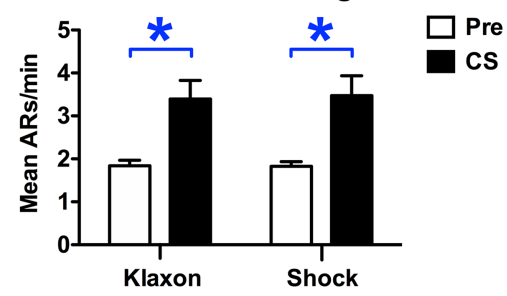

Figure 1. (A) The experimental design used to compare shock and klaxon for their ability to elicit freezing or transfer. Percent time freezing to the tone for subjects trained with klaxon $(\mathrm{Kx})$ and shock (Sk) are shown in $B$ ( $n=8$ per group). Avoidance responses (ARs) during threesession blocks of Sidman avoidance training are shown in $C$ for a different group of rats. Response per minute during the pre-CS (conditioned stimulus) and CS periods during the transfer testing phase are shown in $D$. Following elimination of poor avoiders in this group of 16 rats, six subjects remained in group Klaxon, while group Shock ultimately included five subjects. Asterisks represent statistical significance at the $5 \%$ level.

(see Fig. 2). Another group of subjects had odor paired with tone and were tested for the tone's ability to support transfer. Shuttle rates in these groups were compared with control groups exposed to water instead of urine either during Pavlovian training or transfer testing. All groups acquired avoidance comparably over training blocks $\left(F_{\text {Block }(4,68)}=72.85, \quad P<0.001, \quad F_{\text {Group }(3,17)}=0.13, P=0.94\right.$, $F_{\text {Block }{ }^{*} \operatorname{Group}(12,68)}=0.68, P=0.77$ ) (see Fig. 2B). Transfer testing showed that neither a cue for odor, nor the odor itself had any influence over shuttle rates $\left(F_{\text {Interval }(1,17)}=4.12, P=0.06, F_{\text {Group }(3,17)}=\right.$ 1.24, $P=0.33, F_{\text {Interval }^{*} \operatorname{Group}(3,17)}=0.53, P=0.67$ ) (see Fig. 2C). A follow up test in a nonavoidance context showed that the fox urine produced significantly more freezing than water when avoidance responding was not available $\left(t_{(15)}=6.44, P<0.001\right)$ (see Fig. 2D).

\section{Aversive motivation alone is not sufficient to generate PIT} Some conceptualizations of motivation envision mutually antagonistic appetitive and aversive systems where positive stimuli engage an appetitive center and suppress an aversive counterpart, vice versa for negative valence cues (Konorski 1948). This view has received empirical support from studies of motivational interactions 
A

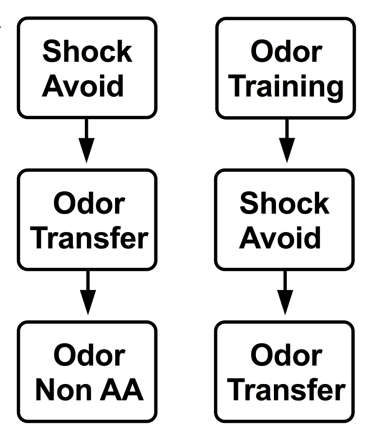

B

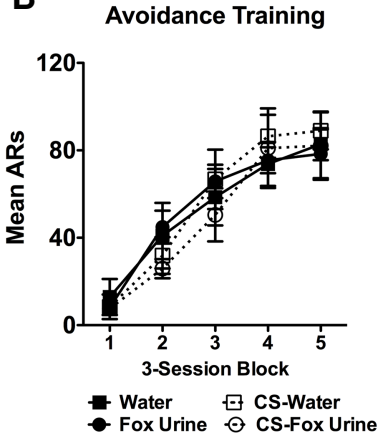

C

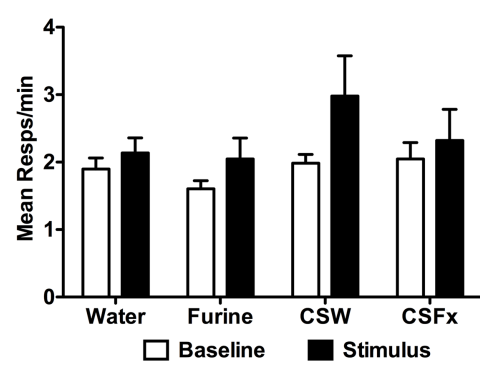

D Non AA Cx

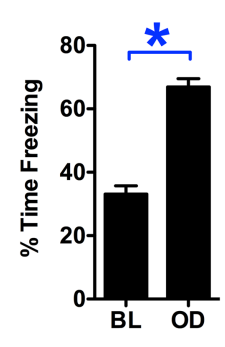

Figure 2. (A) The experimental design used to evaluate predator odor effects of freezing and active avoidance. (B) Avoidance responding for three-session blocks during the Sidman avoidance training phase. (C) Responses per minute during the pre-CS and CS periods for each group tested for aversive transfer. (Furine) fox urine, (CSW) CS water, (CSFx) CS fox urine. (D) Percent time freezing in a nonavoidance context (i.e., a standard Pavlovian chamber) during the baseline (BL) and odor presentation period (OD). Starting with samples of six rats per group, one animal was eliminated from each condition for poor performance with the exception of the water exposed control group, in which all six rats successfully acquired avoidance responding. Asterisks represent statistical significance at the $5 \%$ level.

where cues from opposing motivational/associative classes are shown to be functionally equivalent (Dickinson and Pearce 1977; Dickinson and Dearing 1979; Nasser and McNally 2012). According to this view, a cue that predicts the absence of food (i.e., an appetitive inhibitor) and one that predicts the presence of shock (i.e., an aversive excitor) should both engage "aversiveness" and should, therefore, support similar kinds of motivational effects. For example, Dickinson and Dearing (1979) showed that both appetitive inhibitors and aversive excitors can facilitate (or super condition) learning to a novel cue paired with an outcome from the opposite motivational class. Specifically, an appetitive inhibitor facilitated fear learning, while an aversive excitor enhanced appetitive conditioning. To determine whether aversive PIT and active avoidance are sensitive to these kinds of motivational interactions, we evaluated the capacity of an appetitive inhibitor (i.e., a cue predicting the absence of food) to enhance shuttle rates for subjects trained to avoid shock.

Following magazine training, subjects underwent discrimination training where a tone was trained as a conditioned inhibitor for food (see Fig. 3). Trials of a light alone ended with food presentations, while light-tone compound trials did not. Control subjects received identical stimulus experiences, but food was randomly delivered throughout their sessions. Discrimination subjects successfully suppressed responding to the compound over training and approach during the light alone trials $\left(F_{\operatorname{Day}(15,135)}=8.71, P<\right.$ $0.001, \quad F_{\text {Stimulus }(1,9)}=19.13, \quad P<0.01, \quad F_{\text {Day } * \text { Stimulus }(15,135)}=17.55$,
$P<0.001$ ) (see Fig. 3B). Control subjects, comparatively, showed flat responding across training $\left(F_{\operatorname{Day}(15,135)}=1.51, P=0.11\right.$, $F_{\text {Stimulus }(1,9)}=4.88, \quad P=0.054, \quad F_{\text {Day }}{ }$ Stimulus $\left.(15,135)=0.83, \quad P=0.64\right)$ (see Fig. 3C). All subjects were then trained on shock-avoidance in the shuttle boxes where both groups acquired shuttling over sessions comparably $\left(F_{\text {Block }(4,72)}=36.04, P<0.01, F_{\text {Group }(1,18)}=0.08, P=\right.$ $0.78, F_{\text {Block }^{*} \text { Group }(4,72)}=0.42, P<0.79$ ) (see Fig. 3D). After a reminder discrimination session, subjects underwent transfer tests in the shuttle boxes. These tests found that the ability of an appetitive inhibitor to generate aversive transfer was no stronger than that of the untrained tone in the control group $\left(F_{\text {Interval }(1,18)}=1.9, P=0.19\right.$, $F_{\text {Group }(1,18)}=0.91, P=0.35, F_{\text {Interval }^{*} \operatorname{Group}(1,18)}=0.33, P=0.58$ ) (see Fig. 3E).

To confirm that the tone had acquired true inhibition in discrimination subjects, these subjects were randomly split into two groups that underwent summation and retardation testing independently (Rescorla 1969). Summation testing found that the tone effectively reduced magazine approach to a novel appetitive excitor $\left(t_{(9)}=2.66, P=0.03\right.$ ) (see Fig. 3F). Additionally, when trained as an appetitive excitor relative to another, untrained cue (i.e., flashing light), the untrained cue acquired excitation significantly more quickly while the tone's acquisition was retarded by the accrued inhibition $\left(t_{(9)}=4.43, P<0.01\right)$ (see Fig. $3 G$ ).

\section{Discussion}

The studies reported above replicate and extend the aversive Pavlovian-instrumental transfer phenomenon in a number of ways. A shock-paired cue was shown capable of enhancing active avoidance as was a cue paired with a different aversive event, a klaxon horn. While previous studies (Campese et al. 2017a) showed that subjects trained to avoid shock demonstrated transfer to a shock paired cue, as well as a klaxon-paired cue, the current findings were observed using a between-subjects design, making it less likely that this result depends on generalization. This is an encouraging step toward using aversive PIT to isolate different forms of aversive motivation (i.e., sensory specific versus general).

Furthermore, the class of stimulus capable of harnessing this kind of motivation was more specifically tied to acquired Pavlovian motivation. Innate threat stimuli such as fox urine, which caused significant freezing responses, were not capable of augmenting avoidance. One would expect that the predator odor might suppress avoidance by increasing freezing, however, this was not observed. Previous studies with avoidance have been interpreted as suggesting that reductions in passive behaviors like freezing are replaced with some sense of "agency" or control over emotional reactivity (Moscarello and Hartley 2017). Indeed, studies using aversive PIT have shown that much like extinction, conditioned freezing behaviors are reduced following avoidance. However, unlike extinction, these reductions in defensive responding survive the passage of time and changes to test contexts (Campese et al. 2017b). It is possible that the failure of predator odor to suppress avoidance behavior reflects this change in how aversive threats are processed following avoidance. However, it could also be argued that relative to shock, predator odor is simply a less aversive outcome. Exposure to the more potent stimulus in the avoidance context could have produced a contrast effect rendering it not threatening in that environment (Crespi 1942; Flaherty 1982). Similarly, a cue paired with predator odor was not successful at modulating avoidance responding. Comparable null findings have been reported with traditional freezing measures (Wallace and Rosen 2000; McGregor et al. 2002; Blanchard et al. 2003).

Moreover, it was shown that general aversive motivation is not sufficient to drive aversive PIT. A signal for the absence of 
A

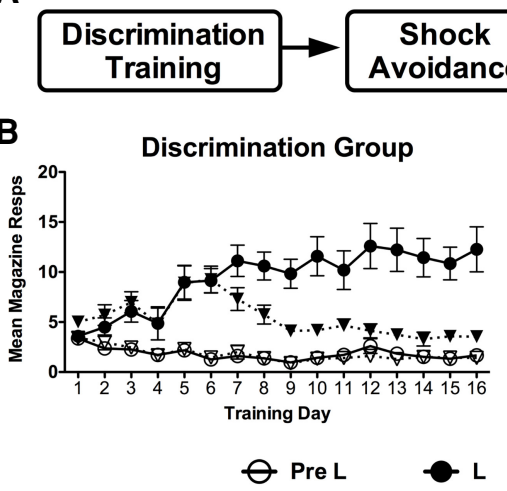

D

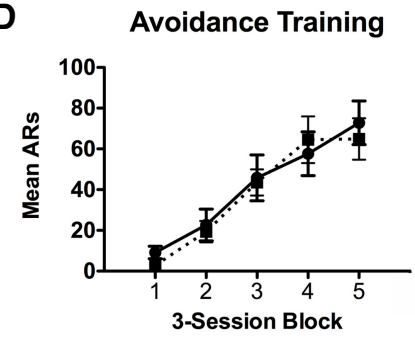

$\mathbf{F}$

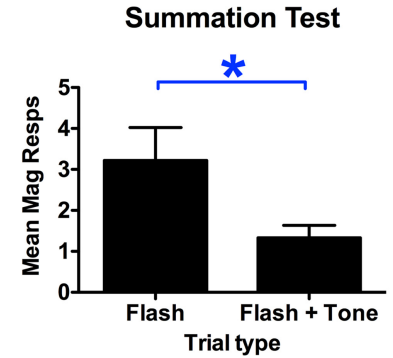

E
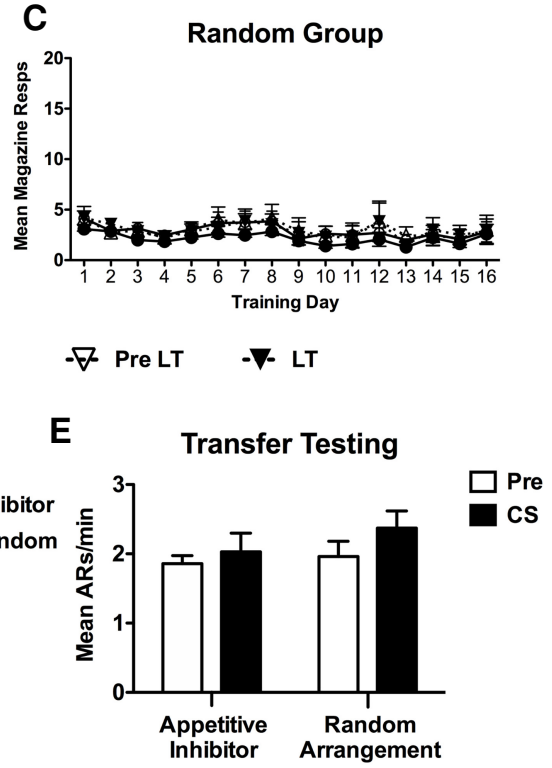

G

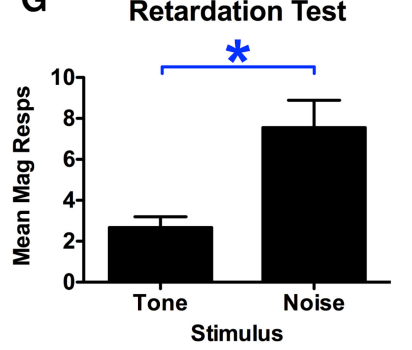

Figure 3. (A) The procedure used to evaluate whether an appetitive inhibitor can generate aversive PIT. Note that prior to discrimination training, 24 subjects received $10 \mathrm{~d}$ of avoidance training in order to eliminate poor performers. After four subjects were removed, the remaining good performers were randomly assigned to either the discrimination training $(n=10)$ or control $(n=10)$ condition, and then proceeded to magazine training. Following appetitive training, subjects received an additional five sessions of avoidance training, a discrimination reminder session, then transfer testing. $(B, C)$ Magazine approach responding during discrimination phase for trained and control subjects, respectively. (D) Avoidance responses during the Sidman training phase for both the discrimination (inhibitor) and random control group. Responses per minute during pre-CS and CS periods for the transfer test phase are shown for the two groups in $E$. Magazine responding is shown for summation $(F)$ and retardation $(G)$ tests as well. Asterisks represent statistical significance at the $5 \%$ level.

food was not capable of augmenting avoidance responding, despite being shown to possess true inhibitory properties. It should be noted that this manipulation was intended only to cause general aversive processing, which previous work suggests it does (Dickinson and Dearing 1979). However, while this class of stimulus may be functionally equivalent to more traditional aversive cues, is not likely perceptually equivalent in terms of aversiveness. Nevertheless, the tone was shown to effectively reduce appetitive responding to an excitatory cue other than that with which it was trained, and it was also slower to acquire excitation than a novel cue. Together, these findings suggest that aversive PIT it is a phenomenon specific to acquired or conditioned aversive motivation. This may prove to be a useful attribute in developing ways to isolate different forms of motivation for more selective neural analyses. Additionally, it could help guide the development of therapeutic strategies to harness the power of avoidance learning to reduce de- fensive responses and promote active coping in treating humans suffering from disorders of fear and anxiety.

With avoidance-based response learning embedded in a computer game, a number of papers have demonstrated that humans show aversive transfer effects, including general and specific control by Pavlovian cues (Nadler et al. 2011; Lewis et al. 2013; Garofalo and Robbins 2017). While these studies have produced encouraging results using this kind of procedure, imaging and other limitations preclude using this preparation for meaningful circuit analysis. It should be noted that while the procedure we used with rodents and these human procedures have much in common (e.g., negative reinforcement and threat processing), there are limitations in the rodent procedure as well, as it currently stands, regarding response options and reinforcer distinctions. The variety of aversive stimulation practical in the context of these kinds of studies are limited, as is the current apparatus for providing a measure of choice (i.e., beyond response intensity in cue comparison studies). Addressing these issues would serve to provide a very useful juxtaposition between human and rodent studies of this phenomenon.

Aversive Pavlovian-Instrumental transfer has not been thoroughly analyzed in the literature, but the studies reported here add to a growing collection of work that seeks to better understand this phenomenon and apply it to the study of aversive motivation. Given the success this approach has produced in our understanding of appetitive motivation, it is surprising more has not been done previously to develop an analog to such a useful procedure.

\section{Materials and Methods}

\section{Subjects}

Eighty male Sprague-Dawley rats served as subjects in the studies reported below. Rodents were obtained from Hilltop Labs and housed in a vivarium (12:12 light:dark cycle) in standard Plexiglass cages with paper bedding, and ad libitum access to food and water. For appetitive conditioning, subjects were food restricted in order to obtain the desired motivational state, which was defined as $90 \%$ of the subjects free feeding weight. Subjects were maintained within $5 \mathrm{~g}$ of this target by daily feedings of chow rations at the conclusion of each day's training session.

\section{Apparatus}

Studies were mostly conducted in conditioning chambers manufactured by Coulbourn Instruments. Aversive Pavlovian training and test sessions were done in standard size chambers (model no. H10-11R-TC) while avoidance and transfer testing were conducted in two-way shuttle chambers (model no. H10-11R-SC). Auditory stimuli (e.g., $5 \mathrm{kHz}$ tone) and $0.5 \mathrm{~mA}$ scrambled footshocks for 
these sessions were presented using a programmable audio generator (model no. A12-33) and a precision animal shock (model no. H13-15), respectively, both manufactured by Coulbourn. Klaxon horns (114 dB) were manufactured by Wolo (model no. 330).

One milliliter of fox urine (Minnesota Trapline Products) was delivered using syringes mounted in Razel Pumps (Model R-E) with the attached lines leading to a cup in the waste tray below each of the Coulbourn chambers. Urine was loaded into the syringes, followed by $1-\mathrm{mL}$ volume air bubble and an additional $1 \mathrm{~mL}$ of water at the end of the line in order to mask odor. Urine and the water control were delivered at a rate of $4 \mathrm{~mL} / \mathrm{min}$.

Appetitive conditioning sessions were done in Med Associates chambers (model no. ENV-008) that were equipped with 5-W light bulbs and an audio generator card (model no. ANL 926) for stimulus delivery. Standard 45-mg pellets (Test Diet AIN-76A) were delivered to the food cup via a pellet dispenser at specific times and approach behavior was recorded using infrared sensors at the threshold of the food magazines. Follow up tests for conditioned inhibition were done in these chambers and utilized a flashing 30 -sec panel light and a white noise $(80 \mathrm{~dB})$ auditory cue generated using this apparatus.

\section{Procedure}

\section{Pavlovian conditioning}

Three 30-sec presentations of the tone stimulus coterminated with shock $(1 \mathrm{sec})$, or klaxon $(5 \mathrm{sec})$ in a 15 -min training session with a 5-min baseline and fixed 3-min intertrial interval (ITI). Test sessions had the same parameters, but without footshock or klaxon presentations. For sessions involving predator odor, the urine was infused into the chamber after a 10-min baseline period or beginning with the presentation of the CS in the cued preparation.

\section{Appetitive discrimination training}

Subjects were first given baseline avoidance training to eliminate poor performers. Good performers were food restricted and then trained to retrieve food pellets from the food cup over $2 \mathrm{~d}$. In each of these two 20-min sessions, two pellets were delivered to the magazine on a VI60 schedule. Over the next 16 sessions subjects were trained on an appetitive discrimination task where a 30-sec house light was paired with food using a delay conditioning arrangement. A compound stimulus consisting of the house light with tone was presented without food to generate inhibition to the tone. Each 105 min session included 16 light, and 8 light+ tone trials, following a 5-min baseline with a variable 3-min ITI ranging from 1 to $5 \mathrm{~min}$. Summation tests were done by training a flashing light to signal food and then combining this cue with tone to determine the degree of control over magazine responding by the tone. Retardation tests were done by comparing the acquisition of magazine responses to the tone when it was paired with food relative to a novel cue (white noise).

\section{Unsignaled Sidman active avoidance}

Avoidance training was done in the two-way shuttle boxes and consisted of fifteen 25-min sessions. Subjects were placed into the chamber with the house light on and the following training contingencies in effect. A response-shock (R-S) interval of 30-sec was applied over a shock-shock (S-S) interval of $5 \mathrm{sec}$. If subjects failed to shuttle by the end of these intervals, a 1-sec shock was delivered. Shuttle responding produced a period of safety (i.e., the R-S interval) lasting 30-sec. Additionally, the house light was turned off for $0.3 \mathrm{sec}$ as a feedback cue for each shuttle response. Shuttle responses that occurred in the absence of shock were scored as avoidance responses (ARs) and those that were initiated while a shock was present were counted as escape responses (ERs). While performance of ERs terminated ongoing footshock, both ARs and ERs initiated the R-S interval. At the end of the session the house lights were turned off and responses produced no further feedback. Subjects that failed to register two consecutive sessions with at least 20 ARs prior to day 10 of training were classified as poor performers and were removed from the study (see Lazaro-Munoz et al. 2010). Sessions were run 5-6 d per week.

\section{Pavlovian-instrumental transfer (PIT) testing}

PIT testing was conducted over two consecutive days in the shuttle box chambers and included no shocks at all. Following placement in the chamber, subjects shuttled in extinction for $15 \mathrm{~min}$, receiving the blinking house light feedback cue for each shuttle. After 15 min, responses were monitored by the computer running the study to identify the point at which the subject's response rate was at two responses per minute. At this point the tone was presented and it remained on until the subject performed 10 shuttle responses, after which the house light turned off and the session ended. Subjects were removed from the boxes and tested again the next day.

\section{Acknowledgments}

This research was supported by National Institutes of Health grants MH038774 and DA044445 awarded to J.E.L. We thank Christopher K. Cain, Justin M. Moscarello, and Robert M. Sears for discussions related to this work and feedback on an earlier version of the manuscript.

\section{References}

Beckers T, Krypotos AM, Boddez Y, Effting M, Kindt M. 2013. What's wrong with fear conditioning? Biol Psychol 92: 90-96. doi:10.1016/j.biopsycho .2011.12.015

Blanchard DC, Markham C, Yang M, Hubbard D, Madarang E, Blanchard RJ. 2003. Failure to produce conditioning with low-dose trimethylthiazoline or cat feces as unconditioned stimuli. Behav Neurosci 117: 360-368. doi:10.1037/0735-7044.117.2.360

Bolles RC. 1972. The avoidance learning problem. In The psychology of learning and motivation (ed. Bower GH, Spence JT), pp. 97-145. Academic Press, Oxford.

Bouton ME. 2004. Context and behavioral processes in extinction. Learn Mem 11: 485-494. doi: 10.1101/lm.78804

Bouton ME, Westbrook RF, Corcoran KA, Maren S. 2006. Contextual and temporal modulation of extinction: behavioral and biological mechanisms. Biol Psychiatry 60: 352-360. doi:10.1016/j.biopsych.2005 .12 .015

Bravo-Rivera C, Roman-Ortiz C, Brignoni-Perez E, Sotres-Bayon F, Quirk GJ. 2014. Neural structures mediating expression and extinction of platform-mediated avoidance. J Neurosci 34: 9736-9742. doi:10.1523/ JNEUROSCI.0191-14.2014

Cain CK. 2019. Avoidance problems reconsidered. Curr Opin Behav Sci 26: 917. doi: 10.1016/j.cobeha.2018.09.002

Campese V, McCue M, Lázaro-Muñoz G, LeDoux JE, Cain CK. 2013. Development of an aversive Pavlovian-to-instrumental transfer task in rat. Front Behav Neurosci 7: 176. doi:10.3389/fnbeh.2013.00176

Campese VD, Kim J, Lázaro-Muñoz G, Pena L, LeDoux JE, Cain CK. 2014. Lesions of lateral or central amygdala abolish aversive

Pavlovian-to-instrumental transfer in rats. Front Behav Neurosci 8: 161 doi:10.3389/fnbeh.2014.00161

Campese VD, Kim IT, Rojas G, LeDoux JE. 2017a. Pavlovian extinction and recovery effects in aversive Pavlovian to instrumental transfer. Front Behav Neurosci 11: 179. doi.org/10.3389/fnbeh.2017.00179

Campese VD, Soroeta JM, Vazey EM, Aston-Jones G, LeDoux JE, Sears RM. $2017 \mathrm{~b}$. Noradrenergic regulation of central amygdala in aversive Pavlovian-to-instrumental transfer. eNeuro 4: ENEURO.0224-17.2017. doi:10.1523/ENEURO.0224-17.2017

Campese VD, Kim IT, Hou M, Gupta S, Draus C, Kurpas B, Burke K, LeDoux JE. 2019. Chemogenetic inhibition reveals that processing relative but not absolute threat requires basal amygdala. J Neurosci 39: 8510-8516. doi:10.1523/JNEUROSCI.2530-18.2019

Corbit LH, Balleine BW. 2016. Learning and motivational processes contributing to Pavlovian-Instrumental Transfer and their neural bases: dopamine and beyond. Curr Top Behav Neurosci 27: 259-289. doi:10 $.1007 / 7854 \_20153388$

Corbit LH, Janak PH, Balleine BW. 2007. General and outcome-specific forms of Pavlovian-instrumental transfer: the effect of shifts in motivational state and inactivation of the ventral tegmental area. Eur J Neurosci 26: 3141-3149. doi:10.1111/j.1460-9568.2007.05934.x

Crespi LP. 1942. Quantitative variation of incentive and performance in the white rat. Am J Psychol 55: 467-517. doi:10.2307/141712 
Delgado MR, Olsson A, Phelps EA. 2006. Extending animal models of fear conditioning to humans. Biol Psychol 73: 39-48. doi:10.1016/j .biopsycho.2006.01.006

Diaz-Mataix L, Debiec J, LeDoux JE, Doyere V. 2011. Sensory-specific associations stored in the lateral amygdala allow for selective alteration of fear memories. J Neurosci 31: 9538-9543. doi:10.1523/JNEUROSCI $.5808-10.2011$

Dickinson A, Dearing MF. 1979. Appetitive-aversive interactions and inhibitory processes. In Mechanism of learning and motivation (ed. Dickinson A, Boakes RA), pp. 203-231. Erlbaum, Hillsdale, NJ.

Dickinson A, Pearce JM. 1977. Inhibitory interactions between appetitive and aversive stimuli. Psychol Bull 84: 690-711. doi:10.1037/0033-2909 .84 .4 .690

Dickinson A, Campos J, Varga ZI, Balleine B. 1996. Bidirectional instrumental conditioning. Q J Exp Psychol B 49: 289-306. doi:10.1080/ 713932637

Dickinson A, Smith J, Mirenowicz J. 2000. Dissociation of Pavlovian and instrumental incentive learning under dopamine antagonists. Behav Neurosci 114: 468-483. doi: $10.1037 / 0735-7044.114 .3 .468$

Estes WK. 1943. Discriminative conditioning. I. A discriminative property of conditioned anticipation. J Exp Psychol 32: 150-155. doi:10.1037/ h0058316

Estes W. 1948. Discriminative conditioning. II. Effects of a Pavlovian conditioned stimulus upon a subsequently established operant response. J Exp Psychol 38: 173-177. doi:10.1037/h0057525

Fanselow MS. 1997. Species-specific defense reactions: retrospect and prospect. In Learning, motivation, and cognition: the functional behaviorism of Robert C. Bolles (ed. Bouton ME, Fanselow MS), pp. 321-341. American Psychological Association, Washington, DC.

Fanselow MS, Lester LS. 1988. A functional behavioristic approach to aversively motivated behavior: predatory imminence as a determinant of the topography of defensive behavior. In Evolution and learning (ed. Bolles RC, Beecher MD), pp. 185-211. Erlbaum, Hillsdale, NJ.

Flaherty CF. 1982. Incentive contrast. A review of behavioral changes following shifts in reward. Anim Learn Behav 10: 409-440. doi:10.3758/ BF03212282

Garofalo S, Robbins TW. 2017. Triggering avoidance: dissociable influences of aversive Pavlovian conditioned stimuli on human instrumental behavior. Front Behavi Neurosci 11: 63. doi:10.3389/fnbeh.2017.00063

Gillan CM, Morein-Zamir S, Urcelay GP, Sule A, Voon V, Apergis-Schoute AM, Robbins TW. 2014. Enhanced avoidance habits in obsessive-compulsive disorder. Biol Psychiatry 75: 631-638. doi:10 $.1016 /$ j.biopsych.2013.02.002

Hall J, Parkinson JA, Connor TM, Dickinson A, Everitt BJ. 2001. Involvement of the central nucleus of the amygdala and nucleus accumbens core in mediating Pavlovian influences on instrumental behavior. Eur I Neurosci 13: 1984-1992. doi:10.1046/j.0953-816x.2001.01577.x

Herry C, Johansen JP. 2014. Encoding of fear learning and memory in distributed neuronal circuits. Nat Neurosci 17: 1644-1654. doi:10.1038/ nn.3869

Hofmann SG. 2007. Cognitive processes during fear acquisition and extinction in animals and humans: implications for exposure therapy of anxiety disorders. Clin Psychol Rev 28: 199-210. doi:10.1016/j.cpr.2007 .04 .009

Holland PC. 2004. Relations between Pavlovian-instrumental transfer and reinforcer devaluation. J Exp Psychol Anim Behav Process 30: 104-117. doi:10.1037/0097-7403.30.2.104

Holland PC, Gallagher M. 2003. Double dissociation of the effects of lesions of basolateral and central amygdala on conditioned stimulus-potentiated feeding and Pavlovian-instrumental transfer. Eur J Neurosci 17: 1680-1694. doi:10.1046/j.1460-9568.2003.02585.x

Kim JJ, Jung MW. 2018. Fear paradigms: the times they are a-changin'. Curr Opin Behav Sci 24: 38-43. doi:10.1016/j.cobeha.2018.02.007

Kim H, Shimojo S, O'Doherty JP. 2006. Is avoiding an aversive outcome rewarding? Neural substrates of avoidance learning in the human brain PLoS Biol 4: e233. doi:10.1371/journal.pbio.0040233

Konorski J. 1948. Conditioned reflexes and neuron organization. Cambridge University Press, New York.

Krabbe S, Gründemann J, Lüthi A. 2018. Amygdala inhibitory circuits regulate associative fear conditioning. Biol Psychiatry 83: 800-809. doi:10.1016/j.biopsych.2017.10.006

Kruse JM, Overmier JB, Konz WA, Rokke E. 1983. Pavlovian conditioned stimulus effects upon instrumental choice behavior are reinforcer specific. Learn Motiv 14: 165-181. doi:10.1016/0023-9690(83)90004-8

Krypotos AM, Effting M, Kindt M, Beckers T. 2015. Avoidance learning: a review of theoretical models and recent developments. Front Behav Neurosci 9: 189. doi:10.3389/fnbeh.2015.00189
Lazaro-Munoz G, LeDoux JE, Cain CK. 2010. Sidman instrumental avoidance initially depends on lateral and basal amygdala and is constrained by central amygdala-mediated Pavlovian processes. Biol Psychiatry 67: 1120-1127. doi:10.1016/j.biopsych.2009.12.002

LeDoux JE, Moscarello J, Sears R, Campese VD. 2016. The birth, death and resurrection of avoidance: a reconceptualization of a troubled paradigm. Mol Psychiatry 22: 24-36. doi:10.1038/mp.2016.166

Lewis AH, Niznikiewicz MA, Delamater AR, Delgado MR. 2013. Avoidance-based human Pavlovian-to-instrumental transfer. Eur J Neurosci 38: 3740-3748. doi:10.1111/ejn.12377

Maren S, Fanselow MS. 1996. The amygdala and fear conditioning: has the nut been cracked? Neuron 16: 237-240. doi:10.1016/S0896-273(00) 80041-0

Markowitz S, Fanselow M. 2020. Exposure therapy for post-traumatic stress disorder: factors of limited success and possible alternative treatment. Brain Sci 10: 167. doi:10.3390/brainsci10030167

McGregor IS, Schrama L, Ambermoon P, Dielenberg RA. 2002. Not all 'predator odours' are equal: cat odour but not 2,4,5 trimethylthiazoline (TMT; fox odor) elicits specific defensive behaviours in rats. Behav Brain Res 129: 1-16. doi:10.1016/S0166-4328(01)00324-2

Meulders A. 2020. Fear in the context of pain: lessons learned from 100 years of fear conditioning research. Behav Res Ther 131: 103635. doi:10.1016/j .brat.2020.103635

Milad MR, Quirk GJ. 2012. Fear extinction as a model for translational neuroscience: ten years of progress. Аnпu Rev Psychol 63: 129-151. doi:10.1146/annurev.psych.121208.131631

Moscarello JM, Hartley CA. 2017. Agency and the calibration of motivated behavior. Trends Cogn Sci 21: 725-735. doi:10.1016/j.tics.2017.06.008

Nadler N, Delgado MR, Delamater AR. 2011. Pavlovian to instrumental transfer of control in a human learning task. Emotion 11: 1112-1123. doi:10.1037/a0022760

Nasser HM, McNally GP. 2012. Appetitive-aversive interactions in Pavlovian fear conditioning. Behav Neurosci 126: 404-422. doi:10.1037/a0028341

Ranaldi R, Egan J, Kest K, Fein M, Delamater AR. 2009. Repeated heroin in rats produces locomotor sensitization and enhances appetitive Pavlovian and instrumental learning involving food reward. Pharmacol Biochem Behav 91: 351-357. doi:10.1016/j.pbb.2008.08.006

Rauch SL, Shin LM, Phelps EA. 2006. Neurocircuitry models of posttraumatic stress disorder and extinction: human neuroimaging research-past, present, and future. Biol Psychiatry 60: 376-382. doi:10 $.1016 /$ j.biopsych.2006.06.004

Rescorla RA. 1969. Pavlovian conditioned inhibition. Psychol Bull 72: 77-94. doi: $10.1037 / \mathrm{h} 0027760$

Rescorla RA. 1974. Effect of inflation of the unconditioned stimulus value following conditioning. J Comp Physiol Psychol 86: 101-106. doi:10 $.1037 /$ h0035964

Rescorla RA. 1994. Control of instrumental performance by Pavlovian and instrumental stimuli. J Exp Psychol Anim Behav Process 20: 44-50. doi:10 $.1037 / 0097-7403.20 .1 .44$

Rescorla RA, Solomon RL. 1967. Two process learning theory: relationships between Pavlovian conditioning and instrumental learning. Psychol Rev 74: $151-182$. doi:10.1037/h0024475

Shiflett MW, Balleine BW. 2010. At the limbic-motor interface: disconnection of basolateral amygdala from nucleus accumbens core and shell reveals dissociable components of incentive motivation. Eur J Neurosci 32: 1735-1743. doi:10.1111/j.1460-9568.2010.07439.x

Sidman M. 1953. Avoidance conditioning with brief shock and no exteroceptive warning signal. Science 118: 157-158. doi:10.1126/ science.118.3058.157

Wallace KJ, Rosen JB. 2000. Predator odor as an unconditioned fear stimulus in rats: elicitation of freezing by trimethylthiazoline, a component of fox feces. Behav Neurosci 114: 912-922. doi:10.1037/0735-7044.114.5 .912

Wise RA, Koob GF. 2014. The development and maintenance of drug addiction. Neuropsychopharmacology 39: 254-262. doi:10.1038/npp .2013 .261

Wyvell CL, Berridge KC. 2001. Incentive sensitization by previous amphetamine exposure: increased cue-triggered 'wanting' for sucrose reward. J Neurosci 21: 7831-7840. doi:10.1523/JNEUROSCI $.21-19-07831.2001$

Received July 3, 2020; accepted in revised form August 18, 2020. 


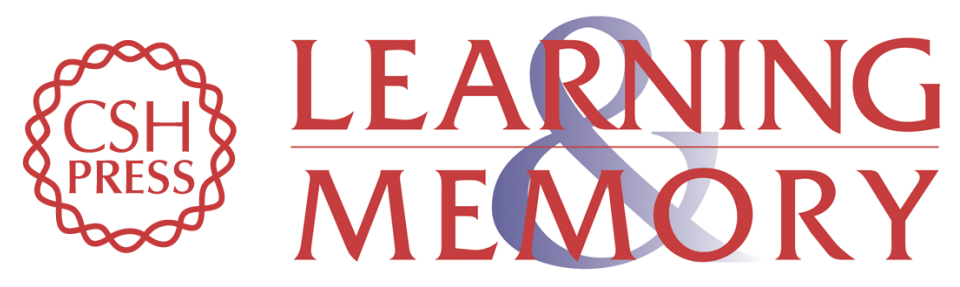

\section{Motivational factors underlying aversive Pavlovian-instrumental transfer}

Vinn D. Campese, lan T. Kim, Botagoz Kurpas, et al.

Learn. Mem. 2020, 27:

Access the most recent version at doi:10.1101/Im.052316.120

References This article cites 56 articles, 7 of which can be accessed free at:

http://learnmem.cshlp.org/content/27/11/477.full.html\#ref-list-1

Creative This article is distributed exclusively by Cold Spring Harbor Laboratory Press for the

Commons

first 12 months after the full-issue publication date (see

License

http://learnmem.cshlp.org/site/misc/terms.xhtml). After 12 months, it is available under a Creative Commons License (Attribution-NonCommercial 4.0 International), as described at http://creativecommons.org/licenses/by-nc/4.0/.

Email Alerting
Service

Receive free email alerts when new articles cite this article - sign up in the box at the top right corner of the article or click here. 